\title{
Automated combination of bilateral energy contracts negotiation tactics
}

\author{
Angelo Pinto ${ }^{1}$, Tiago Pinto ${ }^{2}$, Francisco Silva ${ }^{1}$, Isabel Praça ${ }^{1}$, Zita Vale ${ }^{1}$, Juan Manuel Corchado ${ }^{2}$ \\ ${ }^{1}$ GECAD - Research Group on Intelligent Engineering and Computing for Advanced Innovation and Development \\ Polytechnic of Porto (ISEP/IPP), Porto, Portugal \\ \{fspsa, icp, zav\}@isep.ipp.pt \\ ${ }^{2}$ BISITE Research Centre, University of Salamanca (USAL), Calle Espejo, 12, 37007 Salamanca, Spain \\ $\{$ tpinto, corchado\}@usal.es
}

\begin{abstract}
This paper addresses the theme automated bilateral negotiation of energy contracts. In this work, the automatic combination between different negotiation tactics is proposed. This combination is done dynamically throughout the negotiation process, as result from the online assessment that is performed after each proposal and counter-proposal. The proposed method is integrated in a decision support system for bilateral negotiations, called Decision Support for Energy Contracts Negotiations (DECON), which in turn is integrated with the Multi-Agent Simulator of Competitive Electricity Markets (MASCEM). This integration enables testing and validating the proposed methodology in a realistic market negotiation environment. A case study is presented, demonstrating the advantages of the proposed approach.
\end{abstract}

Index Terms - Automated Negotiation, Bilateral Contracts, Decision Support Systems, Electricity Markets, Negotiation Strategies

\section{INTRODUCTION}

Many changes have occurred in the electricity market during the last decades, including its liberalization. Therefore, today these markets are very complex and unpredictable [1]. Beyond that, there are many markets around the world, each of them with its own rules, and some of them operating in more than one country. In addition, there are different types of markets. Some European examples are MIBEL - Iberian market [2], the northern Europe market Nord Pool Spot [3] and the EPEX Spot [4] which works in Germany, France, Austria and Switzerland. Currently the tendency in Europe is to evolve towards continental markets. In fact, countries like Italy, Belgium, Denmark, Finland, France, Germany, Great-Britain, Portugal, Sweden and others have joined in an electricity market for_day-ahead negotiations [5]. In Latin America, some countries have also joined in a common electricity market.

The recent empowerment of consumers as central pieces in future power and energy systems, and the need to guarantee and incentivize the massive integration of renewable energy sources is leading to yet another paradigm shift - the introduction of local energy markets [6]. The introduction of local marketplaces is expected to increase the use of local generation and give the opportunity for consumers to play the so desired active role in this domain. Due to the fact that there are currently many different markets and types of negotiation; and that the tendency is for these negotiation opportunities to further expand; electricity market players, especially sellers, buyers and aggregators, have the increasing necessity to evaluate their investments and optimize their negotiation strategies in order to be able to guarantee as much benefit from energy negotiation as possible [7].

There are several approaches that address the field of decision support for automated negotiation, including in the energy domain, as discussed in section II. However, these approaches share a common gap: the lack of capabilities to adapt the negotiation approach along the negotiation process. The negotiation strategies and tactics are usually defined before the start of the negotiation, and are enforced until the end of the negotiation procedure. This, however, prevents the dynamic online adaptation to the most recent perceived events.

This paper contributes to surpassing this gap by proposing an automated negotiation approach that combines different negotiation tactics throughout the negotiation process, according to the online assessment of the strategies results that is performed after each proposal and counter-proposal. The proposed method is integrated in a decision support system for bilateral negotiations, called Decision Support for Energy Contracts Negotiations (DECON) [8], which in turn is integrated with the Multi-Agent Simulator of Competitive Electricity Markets (MASCEM) [9]. This integration enables the testing and validation of the proposed approach, in a realistic simulated market environment.

After this introductory section, section II presents a discussion on related work, focusing on the field of automated negotiation. Section III described the proposed methodology, and section IV presents the case study that enables assessing the performance of the proposed methodology. Finally, section $\mathrm{V}$ presents the conclusions of this work.

This work has received funding from the European Union's Horizon 2020 research and innovation programme under the Marie Sklodowska-Curie grant agreement No 641794 (project DREAM-GO) and a grant agreement No 703689 (project ADAPT); and from FEDER Funds through COMPETE program and from National Funds through FCT under the project UID/EEA/00760/2013 


\section{RELATED WORK}

The bilateral contracts negotiation process is typically divided into three steps. In the first step, the players define their "objectives, negotiation limits and initial offers" [10], this is called the pre-negotiation step. Afterwards, players try to reach an agreement, using strategies for negotiating. In the final step, called implementation phase, if an agreement has been achieved the contract is put in practice.

Regarding the actual bilateral negotiations, usually there are three main strategies that are used [10]:

- $\quad$ Concession making: a negotiator reduces its profit to be able to make an agreement with the opposing player;

- Competing: a negotiator holds its selling/buying terms and negotiators and tries to persuade the other player to fulfill its terms;

- $\quad$ Problem solving: negotiators work with each other in order to achieve a reasonable price for both. This strategy may be divided into 2 sub-strategies [11], which are logrolling and nonspecific compensation. Logrolling consists in each player conceding in low-priority issues for themselves and highpriority for the other player. In nonspecific compensation, one of the players accomplishes his goals and pays the other for fulfilling its interests.

Strategies can also be classified as one of the following three types $[12,13]$ :

- $\quad$ Time dependent - If a player has a certain deadline while negotiating, the strategy considers it, usually leading to a higher reduction of profits near the deadline;

- Resource dependent - Similar to time dependent strategies, but in this case the factor taken into account is a certain limited resource, which affects the way of negotiating;

- Behaviour dependent - It depends on the behaviour of the opposite player and tries to achieve the best result based in that behaviour.

A recent study developed new tactics for bilateral negotiations [13]. The tactics are called Conceder, Moderate Conceder, Linear, Moderate Hardheaded and Hardheaded. The approaches from these tactics change, respectively, from conceding a lot in prices in the beginning (Conceder) until conceding just a bit in the end (Hardheaded). In the field of automated negotiation of bilateral contracts, the most used learning methods are Bayesian Learning, Non-linear Regression, Kernel Density Estimation and Artificial Neural Networks [14]. An algorithm for choosing the best strategy among a number of available strategies can be found in [15].

Nowadays there is a need to provide decision support to the players in the electricity market. Although there are already some simulators that enable studying specific problems in the power and energy domain, there is a lack of support solutions for the negotiation of bilateral contracts. GECAD's MASCEM simulator already provides support decision for bilateral markets [9], but it is still possible to improve its performance, namely in the negotiation step and in the choice of the best strategy for approaching a negotiation. With this improvement, it is possible to have more profits while selling and buying electricity [8]. The main contributions from this work, towards surpassing the identified gaps are:

- Analysis and development of tactics to be used in the negotiation of bilateral contracts;

- Complete analysis of the best strategy to use as a counter strategy against each opponent at each time;

- Improvement of bilateral negotiations' results.

\section{PROPOSED APPROACH}

This section describes the tactics developed in the scope of this work, as well as the proposed tactics combination. In order to develop the bilateral negotiation tactics, an analysis of possible solutions has been performed. After analyzing some existing tactics it was necessary to formulate mathematically the models that could express the behaviour associated with each tactic. Some of the developed tactics, namely Determined, Anxious, Gluttonous and Moderated, were based in the general principles of the four strategies of ALBidS [16]; however, these have been adapted in the scope of this work.

An important parameter to consider while using these tactics is the price range that a player wants to use for a negotiation. A seller must detail the maximum and minimum price for selling; the maximum price is used as the initial price for negotiating, and the minimum price is used as absolute limit. A buyer has to define the minimum and maximum price that it is willing to pay. The minimum price is used as the initial price in the negotiation. Also, buyers and sellers need to define the maximum number of proposals $N$ that they are willing to make before ending a negotiation. The following sub-sections detail the developed tactics, where Max is the maximum price for selling (for a seller) and for buying (in case of a buyer). Min is the minimum selling price for sellers and minimum (starting) buying price if it is a tactic for buyers. For each proposal, $x$ represents its number and $y$ represents its value.

\section{A. Time-dependent}

\section{1) Determined Seller}

Price is constant throughout negotiation and it is calculated by the average of the maximum and minimum prices defined, as in (1).

$$
y=\frac{\operatorname{Max}+\operatorname{Min}}{2}
$$

\section{2) Moderated Seller}

Price decreases steadily throughout the negotiation. The formalization of this tactic is based on the linear equation, where $b$ is the maximum price and $x$ the number of the proposal, as in (2).

$$
y=-\frac{\operatorname{Max}-\operatorname{Min}}{N} * x+b
$$

\section{3) Gluttonous Seller}

Price descends slightly until the end of the negotiation; when the end is approaching, it declines significantly so that an agreement can be guaranteed. In order to control if the decline is bigger or smaller, a decrease factor represented as $D$, has been added to the equation. Standard value for decrease factor 
$D$ is 0.9 and it can only change between 0.2 and 1.1 . In case $D$ is 0.2 the price almost does not decrease in the end, and in this case it is a very gluttonous seller. If $D=1.1$, the last proposal is almost equal to the minimum price defined in the beginning and the final proposals will be much smaller than previous ones. This tactic is defined as in (3), where $D$ is the decrease factor.

$$
y=\frac{(\operatorname{Max}-\operatorname{Min}) * D}{x-N}+M+\frac{(\operatorname{Max}-\operatorname{Min}) * D}{N}
$$

\section{4) Anxious Seller}

In this tactic, sellers reduce their selling price in the start of the negotiation, with small reductions in the end. A decrease factor $D$ is also used, whose standard value is 0.6 and $D$ can vary between 0.2 and 1.5. The bigger the value, the bigger the initial drop. The tactic is defined as in (4).

$$
y=\frac{\frac{M a x-M i n}{D}}{x+\frac{1}{D}}+\text { Min }
$$

\section{5) Seller-Percentage decrease}

In this case, the price falls in a constant percentage value, represented by $P$, in each step of the negotiation. It gives a seller the possibility to choose the degree of the decrease in price, as in (5).

$$
y=(1-P) *(y(x-1)) ; y(0)=\operatorname{Max}
$$

\section{B. Behaviour-dependent}

This section describes the developed behavior-dependent tactics for sellers. During the negotiation selling prices decrease in a certain percentage, a "buyer percentage" represented by $P \underline{b}$, related with the percentage variation between the two previous offers of the buyer. Furthermore, sellers can choose a "seller percentage" represented by $P \underline{c S}$, allowing them to specify if they want to strictly follow buyers' price variation or have a lower variation. For example, if a buyer offers 50 euros and then rises to 50.5 euros, price variation is $1 \%$, so $P \underline{b}=1 \%$. If a seller decides that $P \underline{c S}=80 \%$ his offers will decrease $0.8 \%(80 \% * 1 \%)$.

$P \underline{b}=$ last offer (buyer)/ second to last offer (buyer), the mathematical formulation of this tactic is represented in (6) and a negotiation using this strategy is illustrated in Fig. 6.

$$
y=y(x-1)-(y(x-1) *(P b-1) * P c s)
$$

Fig. 1 shows an example for this strategy. Seller's maximum and minimum price are $53 € / \mathrm{MWh}$ and $33 € / \mathrm{MWh}$. Buyer's price offers were randomly chosen and $P \underline{c S}=80 \%$.

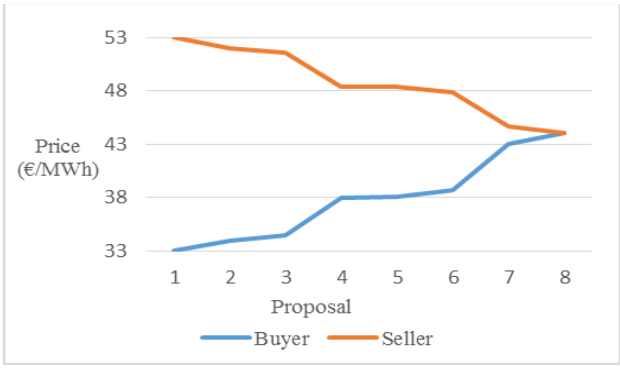

Fig. 1- Seller based on buyer's behaviour

\section{Combined Tactics}

In order to enable the on-line adaptation during the negotiation process, and endow negotiation tactics with some dynamism, some tactics are combined. These procedure for each individual tactic is the same as described before, the main difference is that the player's proposal is based on prices calculated by different strategies throughout the time. These strategies are detailed as follows. The examples shown consider $N=8$.

\section{1) Gluttonous + Anxious seller}

This strategy mixes seller's gluttonous and anxious strategies, allowing a hard approach in the beginning of the negotiation, changing to a conceding strategy in the end. Considering that a seller wants to stop negotiating after 8 proposals, the first 4 proposals are using the Gluttonous tactic and the last 4 using the Anxious tactic. Figure 2 details this strategy.

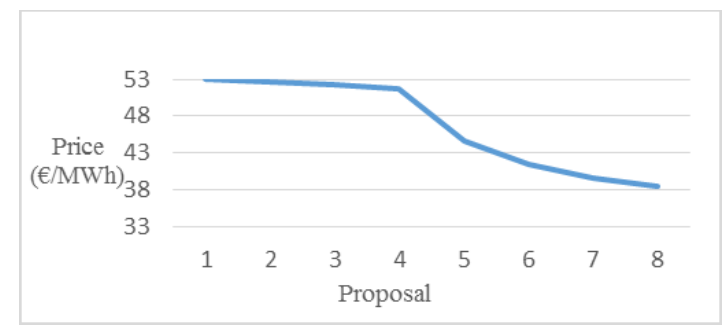

Fig. 2 - Gluttonous + Anxious seller

\section{2) Gluttonous + Anxious + Gluttonous Seller}

This tactic also combines Gluttonous and Anxious tactics, the difference is that in the end Gluttonous tactic is used again. In this situation the first 3 offers are from Gluttonous tactic, offers 4, 5 and 6 from Anxious tactic and 7 and 8 again from Gluttonous approach, as can be seen in Fig. 3. The main advantage of using the Gluttonous approach in the end again in this case is to try getting as much profit as possible, preventing from conceding too much in the final counterproposals.

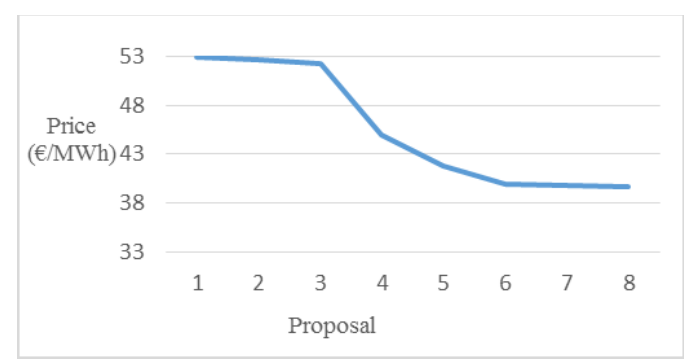

Fig. 3 - Gluttonous + Anxious + Gluttonous Seller

\section{3) Anxious + Gluttonous + Anxious Seller}

In this case, a seller decreases price in the start of the bargaining, then price keeps almost without alterations until the end, finishing with a new yielding. This technique allowed reaching an agreement in most simulated negotiations. At the start there an accentuated decrease in order to make the opponent interested in achieving a fast agreement, but then the seller becomes rigid, bluffing that it is reaching its limit price; however, near the end of the negotiation, it concedes again, in 
order to guarantee the establishment of the agreement. Proposals number 1,2,3,7 and 8 are from Anxious strategy and the remaining from Gluttonous, as showed in Fig 4.

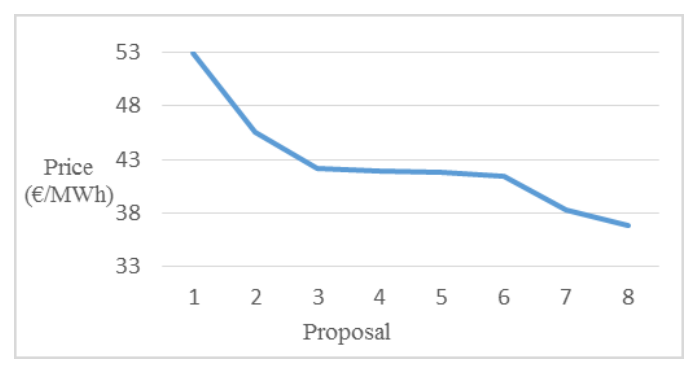

Fig. 4 - Anxious + Gluttonous + Anxious Seller

\section{4) Gluttonous + Anxious + Glut + Anxious + Glut. Seller}

The purpose of this tactic is to make different variations in price throughout the negotiation. Proposals number 1,2,5,6 and 8 are obtained from Gluttonous strategy and 3, 4 and 7 from Anxious strategy. The variation of prices that occurs with this strategy is shown in Fig. 5.

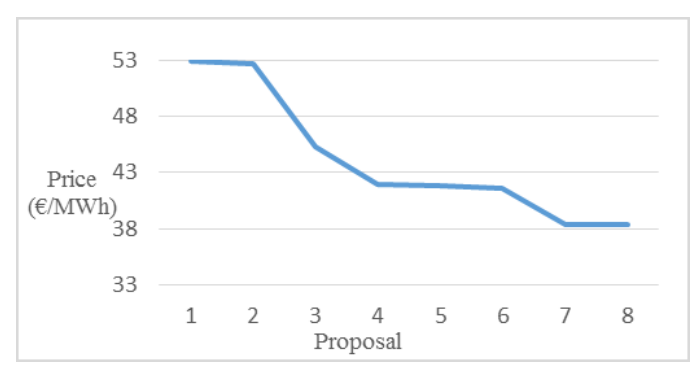

Fig. 5 - Gluttonous + Anxious + Gluttonous + Anxious + Gluttonous Seller

Strategies developed for buyers are equal to the ones present for sellers, the only change is that prices increase instead of decreasing.

\section{RESULTS AND DISCUSSION}

In order to realize which were the best counter-tactics for each of the developed tactics, simulations were performed and the results are shown in Table 1. Lines represent all the developed tactics and columns represent the counter-tactics. For each case, the best counter-tactic is marked with an $X$. As it can be seen, the Gluttonous is the most appropriate strategy against most of the tactics. Maximum and minimum prices were based on the average arithmetic price of the Iberian market in March 2015 [2].

As can be seen by Table 1, in case an opponent uses a Gluttonous tactic, the best approach is to use a Gluttonous+Anxious+Gluttonous strategy. Tables 2 and 3 represent two cases where a seller negotiated with a Gluttonous buyer. In both tables, the first column details if an agreement has been made or not at the end of the negotiation. The second column shows the value of the last proposal made by the seller and the third column shows the number of the last proposal. In the negotiation of Table 2, seller's minimum price was 33 $€ / \mathrm{MWh}, \mathrm{Max}=53 € / \mathrm{MWh}$ and $N=8$. For the buyer $\mathrm{Min}=24$ $€ / \mathrm{MWh}, \mathrm{Max}=44 € / \mathrm{MWh}$ and $N=8$. This case shows clearly that the combination of Gluttonous, Anxious and again Gluttonous strategy is the best approach when negotiating against a Gluttonous buyer. In the case presented in Table 3, the seller minimum price is $40 € / \mathrm{MWh}$ and $\mathrm{Max}=57 € / \mathrm{MWh}$. For the buyer $\mathrm{Min}=31 € / \mathrm{MWh}$ and $\mathrm{Max}=50 € / \mathrm{MWh}$.

Table 2- Negotiations against Gluttonous buyer, case 1
\begin{tabular}{|l|c|c|c|}
\hline Tactic Seller & Agreed & $\begin{array}{c}\text { Last value by } \\
\text { seller }\end{array}$ & $\begin{array}{c}\text { No. of last } \\
\text { proposal }\end{array}$ \\
\hline Anxious & Yes & 36,85 & 8 \\
\hline Determined & No & 43 & 8 \\
\hline Gluttonous & Yes & 37,25 & 8 \\
\hline Moderated & Yes & 35,5 & 8 \\
\hline Percentage 4\% & No & 42,82 & 8 \\
\hline Glu+Anx & Yes & 38,49 & 8 \\
\hline Glu+Anx+Glu & Yes & 39,62 & 8 \\
\hline Anx+Glu+Anx & Yes & 36,85 & 8 \\
\hline G+A+G+A+G & Yes & 38,29 & 8 \\
\hline Behaviour dep. & No & 42,93 & \\
\hline
\end{tabular}

Table 3 - Negotiations against Gluttonous buyer, case 2

\begin{tabular}{|l|c|c|c|}
\hline Tactic Seller & Agreed & $\begin{array}{c}\text { Last value by } \\
\text { seller }\end{array}$ & $\begin{array}{c}\text { No. of last } \\
\text { proposal }\end{array}$ \\
\hline Anxious & Yes & 43,27 & 8 \\
\hline Determined & No & 48,5 & 8 \\
\hline Gluttonous & Yes & 43,61 & 8 \\
\hline Moderated & Yes & 42,13 & 8 \\
\hline Percentage 4\% & No & 46,06 & 8 \\
\hline Glu+Anx & Yes & 44,66 & 8 \\
\hline Glu+Anx+Glu & Yes & 45,62 & 8 \\
\hline Anx+Glu+Anx & Yes & 43,28 & 8 \\
\hline G+A+G+A+G & Yes & 44,5 & 8 \\
\hline Behaviour dep. & No & 48,69 & 8 \\
\hline
\end{tabular}

Table 1 - Strategies and respective counter-strategies

\begin{tabular}{|l|l|l|l|l|l|l|l|l|l|l|}
\hline $\begin{array}{c}\text { Counter } \\
\text { tactic }\end{array}$ & An & Det & Glu & Mod & Perc & Glu+An & Glu+An+Glu & An+Glu+An & G+A+G+A+G & Beh.dep. \\
Tactic & & & & & & & & \\
\hline Anxious & & & $\mathrm{X}$ & & & & & & \\
\hline Determined & & & & $\mathrm{X}$ & & & & & \\
\hline Gluttonous & & & & & & & $\mathrm{X}$ & & \\
\hline Moderated & & & $\mathrm{X}$ & & & & & & \\
\hline Percentage & & & $\mathrm{X}$ & & & & & & \\
\hline Glu+Anx & & & $\mathrm{X}$ & & & & & & \\
\hline Glu+Anx+Glu & & & $\mathrm{X}$ & & & & & & \\
\hline Anx+Glu+Anx & & & $\mathrm{X}$ & & & & & & \\
\hline G+A+G+A+G & & & $\mathrm{X}$ & & & & & & \\
\hline Behaviour dep. & & & $\mathrm{X}$ & & & & & & \\
\hline
\end{tabular}

G,Glu - Gluttonous; A, An,Anx - Anxious; Det - Determined; Mod - Moderated; Perc - Percentage decrease; Beh.dep. - Behaviour dependent 
From Table 2 it is visible that the Gluttonous + Anxious + Gluttonous tactic achieved a price of $39,62 € / \mathrm{MWh}$, while the $2^{\text {nd }}$ best (Gluttonous+Anxious), only got to 38,49 . So, using the best tactic allows a profit of more than $1 € / M W h$. In the case presented in Table 3 , the advantage is not so great, but it is still almost of $1 € / \mathrm{MWh}$, since using Glu+Anx+Glu strategy the seller sold by $45,62 € / \mathrm{MWh}$ and with other strategies it could not get more than $44,66 € / \mathrm{MWh}$. Furthermore, in both cases, when compared against non-mixed strategies, the profit is around $2 € / M W h$. The charts from Fig. 6 and 7 illustrate the negotiations presented in Tables 2 and 3, respectively. All parameters are the same. In both charts the seller is using a mix of the Gluttonous, Anxious and Gluttonous tactics, which proved to be the best against this type of buyers. In Fig. 6 and 7, it is possible to realize why this tactic succeeds against a Gluttonous buyer. It reduces the selling price in the middle of the negotiation to accommodate the buyer's expectations, but keeps a steady price in the end, whereas the buyer tries to achieve an agreement increasing his offers. This allows increasing selling prices against this type of buyer and obtain more profits.

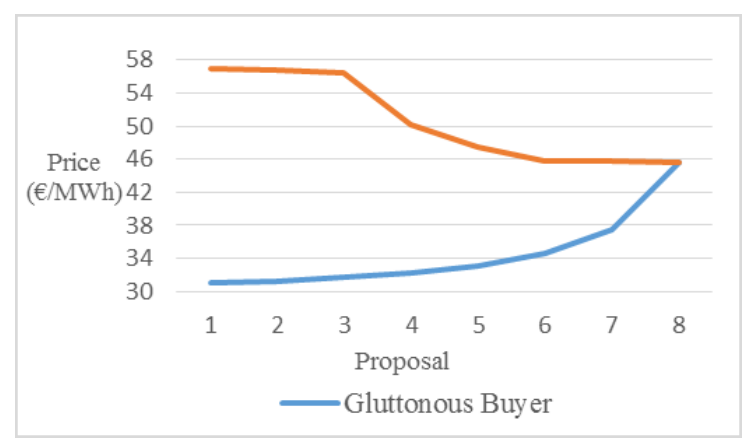

Figure 6 - Seller against Gluttonous buyer, case 1

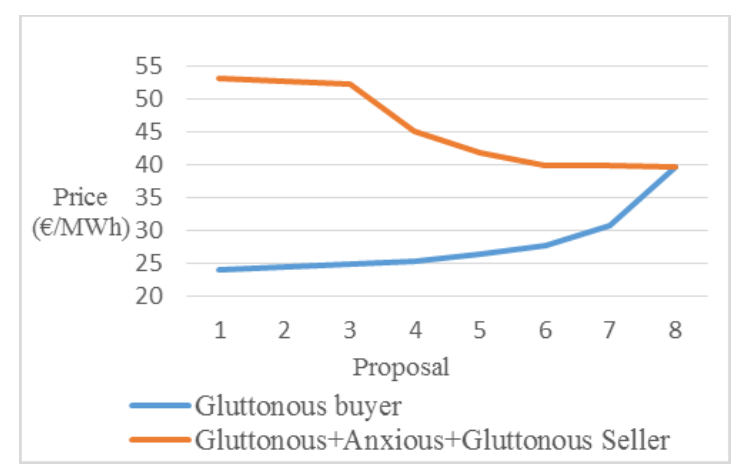

Figure 7 - Seller against Gluttonous buyer, case 2

\section{CONCLUSION}

The complexity of today's electricity markets makes it difficult to negotiate without any help, if players desire to achieve profitable deals. Using specific negotiation strategies that suit each specific opponent is one of the ways to achieve better results in negotiations.

This paper proposed ten strategies for bilateral negotiation in electricity markets. Starting from 4 traditional strategies, more strategies were developed by mixing the initial 4 in order to get a wider range of strategies and provide dynamism and adaptation capabilities to the supported player. Nine of the ten strategies developed are time-dependent and one is behaviourdependent. In order to assess which was the best counterstrategy for each of the ten strategies, several negotiations were simulated using MASCEM and the results are presented. Results show that using a combination of strategies can be useful for some negotiations, as it enables achieving deals that are more advantageous. The findings of this work may be useful not only for electricity markets negotiations, but also in other fields which involve bilateral negotiations.

\section{REFERENCES}

[1] Sioshansi, F.P., "Evolution of Global Electricity Markets - New paradigms, new challenges, new approaches", Academic Press, 2013.

[2] MIBEL - homepage, Available: http://www.mibel.com, accessed on May 2017

[3] Nord Pool - homepage, Available: http://www.nordpoolspot.com, accessed on May 2017

[4] EPEX - homepage, Available: https://www.epexspot.com, accessed on May 2017

[5] APX, Italian borders coupled, 2015, www.apxgroup.com/wpcontent/uploads/2015-02-

24_MRC_PCR_IBWT_Communication_SuccessfulGoLive.pdf, accessed on May 2017.

[6] Olivella-Rosell, P. et al. "Day-ahead micro-market design for distributed energy resources". IEEE International Energy Conference, (2016), 1-6.

[7] T. Pinto, J. Barreto, I. Praça, G. Santos, Z. Vale, and E. J. S. Pires, "Multiagent based metalearner using genetic algorithm for decision support in electricity markets," in 2015 18th International Conference on Intelligent System Application to Power Systems (ISAP), 2015, pp. 1-6.

[8] T. Pinto, Z. Vale, I. Praça, E.J. Solteiro, F. Lopes. 2015. "Decision Support for Energy Contracts Negotiation with Game Theory and Adaptive Learning". Energies.

[9] Pinto, T., Morais, H., Sousa, T.M., Sousa, T., Vale, Z., Praça, I., Faia, R., Solteiro Pires, E.J., "Adaptive Portfolio Optimization for Multiple Electricity Markets Participation" IEEE Transactions on Neural Networks and Learning Systems, in press, August, 2015.

[10] F. Sousa, "Bilateral Contracting in Liberalized Energy Markets: Contracts for Difference and Risk Management," Lisbon, Portugal, Oct2014.

[11] F. Lopes et al., "Multi-agent Simulation of Bilateral Contracting in Competitive Electricity Markets," in 2014 25th International Workshop on Database and Expert Systems Applications, 2014, pp. 131-135.

[12] E. Romanhuki, M. Fuckner, F. Enembreck, B. Avila, and E. E. Scalabrin, "Improving bilateral negotiation with evolutionary learning," in 2008 12th International Conference on Computer Supported Cooperative Work in Design, 2008, pp. 343-348.

[13] S. K. Awasthi, S. R. Vij, D. Mukhopadhyay, and A. J. Agrawal, "Multistrategy based automated negotiation: BGP based architecture," in 2016 International Conference on Computing, Communication and Automation (ICCCA), 2016, pp. 588-593.

[14] T. Baarslag, M. J. C. Hendrikx, K. V. Hindriks, and C. M. Jonker, "Learning about the opponent in automated bilateral negotiation: a comprehensive survey of opponent modeling techniques," Auton Agent Multi-Agent Syst, vol. 30, no. 5, pp. 849-898, Sep. 2016.

[15] L. Ilany and Y. Gal, "Algorithm selection in bilateral negotiation," Auton Agent Multi-Agent Syst, vol. 30, no. 4, pp. 697-723, Jul. 2016.

[16] Z. Vale, T. Pinto, H. Morais, I. Praça, and P. Faria, "VPP's multi-level negotiation in smart grids and competitive electricity markets," in 2011 IEEE Power and Energy Society General Meeting, 2011, pp. 1-8. 